\title{
DEVELOPMENT OF A VISUAL WHOLE LIFE-CYCLE ENERGY ASSESSMENT FRAMEWORK FOR BUILT ENVIRONMENT
}

\author{
Saad Dawood \\ Centre for Construction Innovation \\ and Research, \\ Teesside University \\ Middlesbrough, TS1 3BA, UK
}

\author{
Richard Lord \\ Clean Environment Management \\ Centre \\ Teesside University \\ Middlesbrough, TS1 3BA, UK
}

\author{
Nashwan Dawood \\ Centre for Construction Innovation \\ and Research, \\ Teesside University \\ Middlesbrough, TS1 3BA, UK
}

\begin{abstract}
The United Nations Framework Convention on Climate Change (UNFCC) adopted the Kyoto protocol, establishing legally binding targets for the developed world countries that ratified the protocol. It aims to reduce greenhouse gas emissions by an overall 5\% below 1990 levels during the period between 2008 and 2012. Our review of current literature and research projects in the area of sustainability, energy and assessment applied to built environment identified gaps in current knowledge and tools. There is also a need to integrate sustainability within the whole life cycle of a building from design through construction to operation. This paper aims to give an overall review of the knowledge and technologies in the research area. We present a framework, methodologies and technologies that will facilitate the integration of Environmental Impact Assessment (EIA), Whole Life Cycle Cost Assessment (WLCCA) and Life Cycle Assessment (LCA) using 3D and Building Information Model (BIM) technologies.
\end{abstract}

\section{INTRODUCTION}

The paper is part of the research topic "Integration of 3D with Environmental Impact Assessment at the early design stage". The idea of this research is to create a framework and a prototype that integrates 3D/VR models of buildings with Environmental Impact Assessment, Whole Life Costing and Life Cycle Assessment of the building project during the outline design process. Building information models (BIM) and 3D technology will be used to visualize the result and allow better or more accurate decision making for the project stakeholders.

A comprehensive literature review has been undertaken to identify the state-of-the-art of energy assessment software and the data models available to decision-makers, the methodologies to assess environmental impact and current developments. This review has identified significant gaps in current knowledge and tools. For example, the development of a generic data framework would help decision-makers to accurately estimate the sustainability costs and benefits. The Sustainable Urban Environment evaluation of sustainability tools (Sue-MoT 2003 and Sue-MoT 2004), has revealed a number of key issues:

- Currently Sue-Mot is working to develop an Integrated Sustainability Assessment Toolkit (ISAT) that brings together many approaches, allowing key decision-makers to identify the most appropriate for their project and to combine the results based on their values (El-Haramm et al. 2005).

- There is a need to integrate sustainability within the whole life cycle analysis of a building from design through construction to operation. (Mark et al. 2006).

- We need the use of such tools to become almost synonymous with "green" building.

In addition, many works have been done by other scholars in the field. For example Ness et al. (2007) reported that "Efforts have been made through combining two or more different tools to extend the focus of analysis". Loh et al. (2008) also mentioned that "by making environmental impact analysis and life cycle cost control readily linked to 3D, the value of 3D technology will be enhanced significantly and it will likely result in more use of the technology in the construction process".

The result showed that the individual assessment method does not offer a total solution. It cannot assess human or environmental safety and does not address comprehensive environmental management, cost and LCA. Hence, the individual assessment method by itself is insufficient for decision-making. Thus, we need to bring together many approaches, allowing 
key decision-makers to enhance the accuracy of assessment tool results. Also it would provide a vital tool to bridge the design / operating performance gap by providing the feedback loop that is so lacking at present.

\section{SUSTAINABILITY, ENERGY AND ASSESSMENT APPLIED TO THE BUILT ENVIRONMENT.}

\subsection{Sustainability}

More than 20 years after the concept of sustainability gained international recognition through the Brundtland Commission (World Commission on Environment and Development 1987) it continues to arouse much debate about how it should be defined, interpreted and assessed. It has generated a wealth of research and policy discussion on the meaning, measurability and feasibility of sustainable development. Sustainable development can be defined in a number of ways; Fowke and Prasad (1996) have identified at least 80 different, often competing and sometimes contradictory definitions. Parkin et al. (2003) report over 200 definitions reflecting the complexity and uncertainty over what is to be sustained, by whom, for whom and what is the most desirable means of achieving it. There is a broad consensus that the concept draws together economic, environmental and social objectives with a commonly rehearsed definition being that from the Brundtland Report (WCED 1987), where it is suggested that sustainable development means " development that meets the needs of the present generation without compromising the ability of the future generations to meet their own needs".

According to Sage (1998) "Sustainable development refers to the fulfilment of human needs through simultaneous socioeconomic and technological progress and conservation of earth's natural systems". Integration of environmental, social and economic issues is still a key challenge for the delivery of sustainable development and likewise for sustainability assessment. The growing sustainability challenges are supported by research-based information, tools and techniques. The UK Strategy for Sustainable Development (DEFRA 2005) identified four shared priorities across the UK. They are: Sustainable Consumption and Production; Climate Change and Energy; Natural Resource Protection and Environmental Enhancement, and Sustainable Communities.

Traditional buildings consume large amounts of energy and other natural resources and can harm the environment around them, there is a swelling interest in designing, building, and occupying more environmentally sensitive structures, the benefits associated with sustainable construction can be divided into environmental, economic and social types:

- Environmental benefits include improved air and water quality, reduced energy and water consumption and reduced waste disposal.

- Economic benefits include reduced operating costs, reduced maintenance costs, and increased revenue via sale price or rental.

- Social benefits include enhanced occupant comfort and health, reduced absenteeism and turnover rate, and reduced liabilities.

The sustainability of the built environment is dependent on a fundamental shift in how resources are used (from non renewable to renewable, and from high levels of waste to high levels of reuse and recycling) and from projects based on lowest initial cost to those based on whole life value and full cost accounting (Kibert et al. 2000).

\subsection{Energy Models}

Computer-based simulation methods offer a powerful and flexible tool for building energy analysis (Joseph and Hui 1991) and energy conservation programmes. Since the late 1970s, building energy service programmes (BESPs) developed on mainframe or mini-computers have been used for energy conservation activities. DOE-2 (LBL 1981) and BLAST (BLAST Support Office 1991) are examples of BESPs that can perform detailed hour-by-hour load and energy calculations for each of the 8,760 hours in a year. In order to standardise and facilitate the analysis process, efforts have been made to develop subroutines for automating the simulation process, extracting results, storing and manipulating the voluminous output generated from the simulation runs.

Hui and Cheung (1997) discussed a multi-year (MY) approach to building energy simulation and presented a pilot study in Hong Kong that investigated long-term building energy performance using MY weather data. Building energy simulations in the pilot study were carried out using the DOE-2.1E program. A set of 17 years of hourly weather data (1979-95) was taken as the weather input to drive the simulation. It was found that the MY approach can provide better analysis of long-term building energy performance and climatic properties. Although the MY approach has many advantages, it does require more data and computations. The availability of MY weather data is a critical limiting factor at present. Accurate and reliable weather data are crucial for building energy simulation and analysis. In the past, MY weather data was seldom used in building energy simulation because the costs and time involved are substantial. With the increase of computing power and devel- 
opment of building energy simulation methods, the use of MY weather data becomes more feasible and is worth examining at this stage.

Chirarattananon and Taveekun (2004) tested a model for predicting energy consumption for buildings based on the Overall Thermal Transfer Value (OTTV), Such a building parameter is based on the thermal characteristics of the building (wall composition, glazing type, wall-window ratio, etc.). The OTTV values are then correlated with other parameters such as shading coefficients, lighting and equipment density in equations that are developed for different building occupations (hotels, commercial buildings, hospitals, etc.) and for the different months of the year. The energy consumption of several buildings was audited DOE-2 <http://gundog.lbl.gov/dirsoft/d2whatis.html> and runs were performed in order to validate the model. The proposed model has a fair correlation with the values produced in the auditing process and simulation. The model reproduces the behaviour of the energy consumption profiles but it has poor prediction in several cases, especially for hotels and hospitals, but good predictions for department stores and commercial buildings.

\subsection{State-of-the-art of energy profiling simulation software and Standards}

There are several ways to attempt to model a building and its heat gains from external or internal sources to evaluate a proper operation and audit retrofit actions. These models apply various techniques varying from simple regression to more physically grounded models. A frequent hypothesis for all of these models is that the input variables should be based on realistic data when they are available, otherwise the evaluation of energy consumption might be highly under or over estimated (Alberto et al. 2007).

\subsubsection{Integrated Environmental Solution Ltd $<$ Virtual Environment $>$ software}

Simulation consultants IES Limited have used the building performance modlling capabilities of its $<$ Virtual Environment $>$ software (IES-VE) to help in the development of a given design. The software can compare and contrast how different design choices affect the performance of a wide range of building elements, such as thermal, airflow and lighting performance, energy and $\mathrm{CO}_{2}$ consumption. A structured simulation approach encompasses all the latest cutting edge simulation techniques, for example, external wind studies, thermal, airflow and lighting studies.

Using Heathrow Terminal 5 as a case study $<$ ht $t$ : / / www. iesve.com $>$ Building Services Consulting Engineers and British Airports Authority selected IES Consulting and the IES-EV building simulation software for a number of reasons:

- The unique integrated data model meant that the simulation processed faster and the data and analyses were managed in a controlled and structured manner.

- No special customisation was required, and the software could be adapted to the needs of the project.

- $\quad$ The $<\mathrm{VE}>$ simulates the building as a complete entity, taking into account climate and site as well as factors like light, shade, ventilation, energy, carbon, lifecycle costs, occupant safety and economics.

- Performance analysis provides the qualitative and quantitative data needed to optimise the integrated elements of the design.

- This holistic approach ensures architectural considerations and engineering systems can work together effectively from the start.

- Key decisions can be made much earlier in the design process, maximizing opportunities to reduce the building's energy use and carbon footprint.

- The value for this tool is that it has an in-depth energy analysis by integrating with the Energy Plus.

\subsubsection{Energy Profile Tool}

The Energy Profile Tool <wWw. EnergyProfileTool.com> is a customized, commercially available energy analysis tool developed by EnerSys Analytics Inc. and XModus Software Inc. It allows you to enter information about your facilities and it provides detailed profiles of the energy use, as well as benchmark comparison results. The tool helps to identify opportunities to reduce energy and costs, and take the next steps to long-term savings.

The purpose of energy assessment is to provide information about how energy is used a point of reference for comparisons to other similar facilities, for direction to potential energy savings opportunities. The assessment and recommendations are based upon the information provided to the Energy Profile Tool. It retains detailed information about the information and data that was used to conduct the energy assessment. The Energy Assessment for Sample Large Office is used as a case study.

The accuracy of this assessment and the resulting recommendations are directly influenced by the degree of accuracy of the data that was input to the Energy Profile Tool. In addition to the data inputs, a number of other factors such as weather 
variations, building occupancy and operation schedules can affect energy usage and consequently energy cost savings. Typical characteristics for these other factors were used in the simulation model to calculate energy consumption and conduct this assessment. The assessment is not intended to predict the future effect of any changes made but rather to provide guidance and focus on the greatest potential energy savings opportunities and recommend next steps. It features:

- Comparison of energy consumption and use patterns with other similar facilities assessing current state to develop improvement targets for the future.

- Comparisons of greenhouse gas emissions of the facility with industry averages and an efficient facility (Figure1).

- Energy saving opportunities. The tool gives suggestion about best energy management practices for the building (office equipment, outdoor air, operation and maintenance, HVAC controls and lighting).

- $\quad$ Suggestions for the next steps for improvement.

Potential disadvantages of this tool are:

- It is for existing building use only.

- It can only be used for USA climatic conditions.

- It cannot be integrated with 3D models.

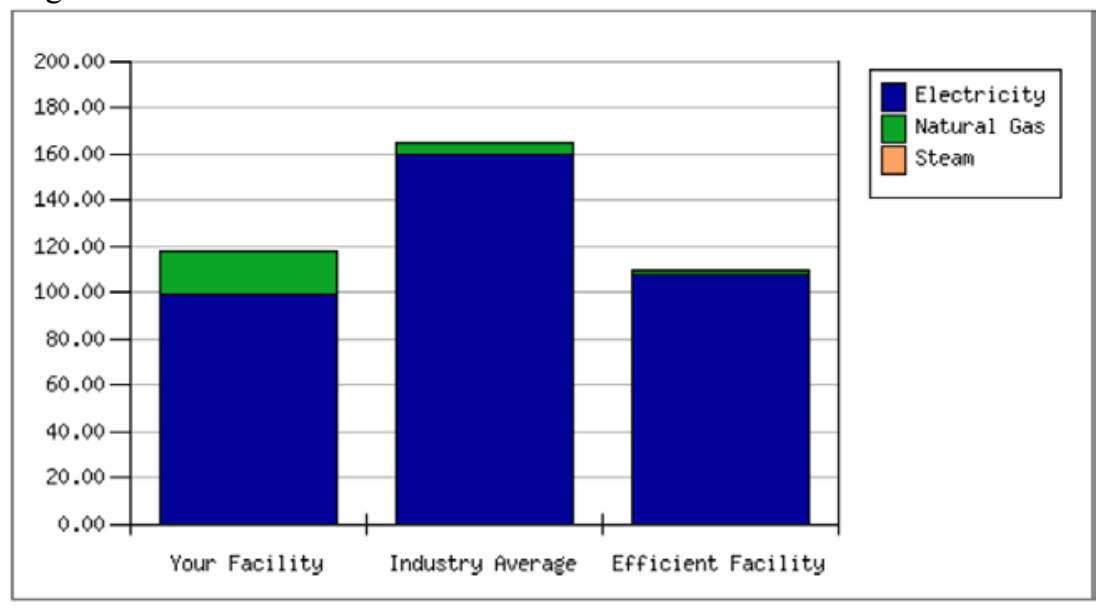

Figure 1: Example of an output from Energy Profile Tool

\subsubsection{Green Star Rating}

Green Star <http://www.gbca.org.au/green-star/> is an Australia National Tools, comprehensive, voluntary environmental rating scheme that evaluates the environmental design and achievements of buildings. Green Star was developed for the property industry in order to: Establish a common language; set a standard of measurement for green buildings; promote integrated, whole-building design; recognize environmental leadership; identify building life-cycle impacts and raise awareness of green building benefits.

Green Star covers a number of categories that assess the environmental impact that result directly from a project's site selection, design, construction and maintenance. The nine categories included within all Green Star rating tools are: Management, Indoor Environment Quality, Energy, Transport, Water, Materials, Land Use \& Ecology and Emissions Innovation. These categories are divided into credits (Figure 2), each of which addresses an initiative that improves or has the potential to improve environmental performance. Points are awarded in each credit for actions that demonstrate that the project has met the overall objectives of Green Star. Once all claimed credits in each category are assessed, a percentage score is calculated and Green Star environmental weighting factors are then applied. Green Star environmental weighting factors vary across states and territories to reflect diverse environmental concerns across Australia. The following are examples of Green Star certified ratings:

- 4 Green Star Certified Rating (score 45-59) signifies 'Best Practice'

- 5 Green Star Certified Rating (score 60-74) signifies 'Australian Excellence'

- 6 Green Star Certified Rating (score 75-100) signifies 'World Leadership' (Figure 3) 


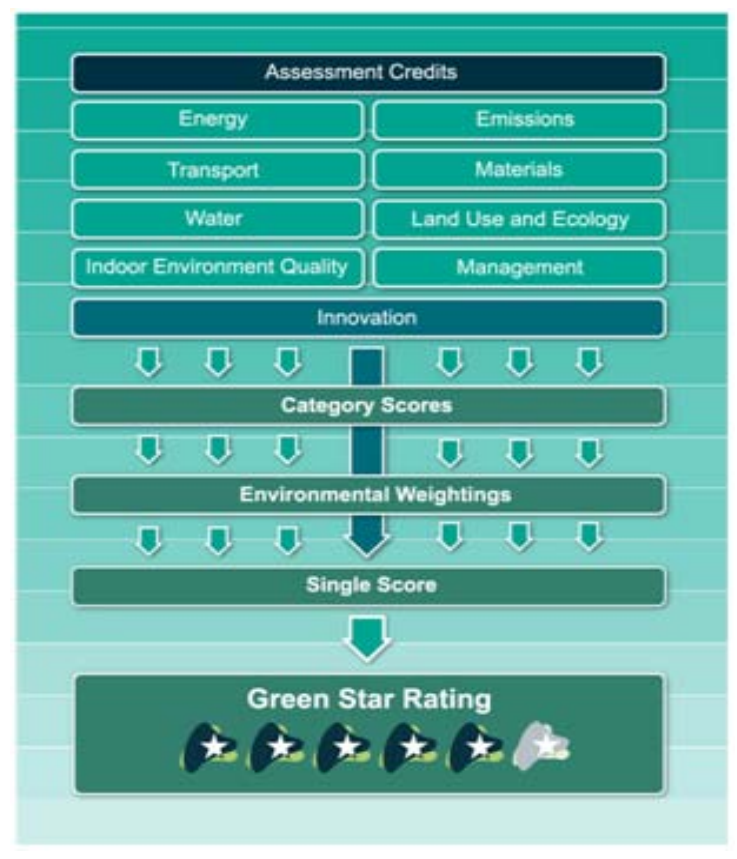

Figure 2: Framework of Green Star Tool

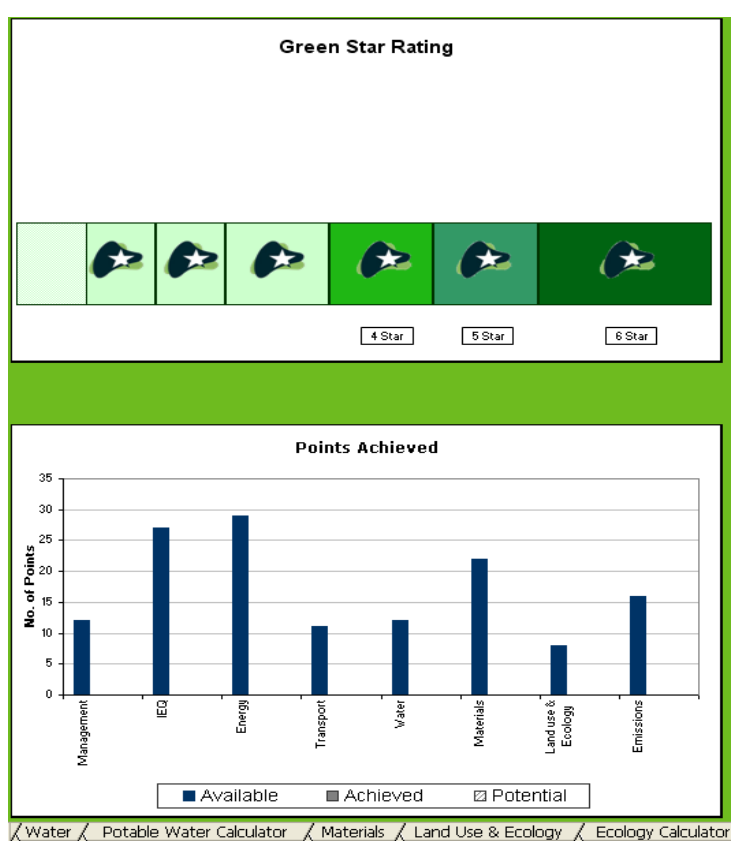

Figure 3: Output from Green Star Tool

\subsubsection{BREEAM scheme:}

BREEAM was released in 1990. The development of building environmental assessment methods was largely an exercise in structuring a broad existing knowledge and considerations into a practical framework, rather than requiring or demanding new research. Now building environmental assessment is a defined realm of enquiry with more rigorous explorations into weighting protocols, performance indicators, effectiveness - market and physical etc (Cole et al. 2005).

The objectives of BREEAM are stated as (Holmes et al. 2000):

- To distinguish buildings of reduced environmental impact in the market place.

- To encourage best environmental practice in building design, operation, management and maintenance.

- To set criteria and standards going beyond those required by law and regulations.

- To raise awareness of owners, occupiers, designers and operators of the benefits of buildings with reduced environmental impact.

Much of the supporting evidence for the success of BREEAM is its influence in changing design and the consequential reduction of environmental damage.

\section{BUILDING INFORMATION MODELS (BIM) AND COMPUTER AIDED DESIGN (CAD) SYSTEMS}

A common definition of a CAD system is "software programs that assist engineers and designers in a wide variety of industries to design and manufacture physical products ranging from buildings, bridges, roads, aircraft, ship and cars to digital cameras, mobile phone, TVs, clothes and of course computers" (CADAZZ 2004).

Eastman (1999), divides the evolution of computer aided design systems for building projects into three stages:

- In the first stage, a CAD system is used only as a geometric editor, which is described as a graphic modelling tool with inputting, outputting and editing functionality;

- In the second stage, a CAD system is defined as "a platform for application development, which allows users to develop specific-purpose applications to be added on CAD platform; to define the specialized entities with their associated geometry, attributes and topological relations; and to provide special operators to edit and manipulate the special objects". Most CAD systems used today are in this stage.

- The third generation of CAD systems involves integrated applications of 3D and solid modelling, object-oriented languages and databases, effective graphical user interfaces and web-based communication. 
Many CAD systems available today are the platforms of further application developments for special purpose implementations. For the separate computational tools to be integrated around a central representation of a building, a building information model, is a new development (Eastman and Siabiris 1995).

The definition given by Autodesk (2003) is that Building Information Modelling is an approach to building design, construction, and management. It supports the continuous and immediate availability of project design scope, schedule, and cost information that is of high quality, reliable, integrated, and fully coordinated. Though it is not itself a technology, it is supported to varying degrees by different technologies.

Differing from a 3D CAD model, a building information model:

- Contains the internal relationships between the building elements, which can enable applications to deal with the consequent alternations caused by the changes of a single building element easily and in a timely fashion.

- May contain properties for each 3D building element, including material, related constructing actions, costs, and so on.

All this information is stored as one integrated data repository. This information can enable the user to easily conduct construction scheduling and costing according to conceptual design and rapidly and precisely cope with any changes. (Fu 2005).

\subsection{Revit building information modelling and Sustainable Design:}

In current practice, many building models do not contain sufficient information for building performance analysis and evaluation. The Revit parametric building modeller represents the building as an integrated database of coordinated information. Beyond graphically depicting the design, much of the data needed for supporting sustainable design is captured naturally as design in the project proceeds. In addition, the integration of Revit Building with commercially available analysis tools greatly simplifies the often cumbersome and difficult analyses. By linking the building model directly to the analyses software, Revit Building gives architects easy access to tools that provide immediate feedback on design alternatives early on in the design process (Autodesk Revit White Paper 2005).

Revit building information modelling can be applied to a variety of sustainable design activities including design optimization, visualization, day-lighting, energy analysis, quantity takeoffs, and specifications management. As building growth intersects with environmental concerns and the rising cost of energy, a growing field within building design has emerged sustainable design, the practice of designing, constructing and operating buildings in a manner that minimizes their environmental impact. The goal of sustainable design is to produce green buildings that are "environmentally responsible and healthy places to live and work" (U.S. Green Building Council, Mission Statement 2004).

Revit Architecture offers a rich set of capabilities that supports better sustainable design decision making. For example:

- Revit Architecture sun studies enable designers to analyze sun positions and solar effects while informing the design process.

- Designers can export building information, including materials and room volumes, to green building extensible markup language (gbXML) to perform energy analysis and study building performance.

- Using design options it is easy to develop or evaluate multiple sustainable design alternatives. Visualize, quantify and present any combination of schemes to inform the decision making process. (Autodesk Revit Architecture 2008).

\section{PROPOSED METHOD AND FRAMEWORK}

The aim is to facilitate the integration of Environmental Impact Assessment, Whole Life Cycle Cost and Life Cycle Assessment with 3D technology / (Revit) BIM. These tools will work together to achieve the main goal, to identify synergy between variables and the result will be visualized by using a BIM, and allow decision - makers to allocate a weighting to the different indicators. 


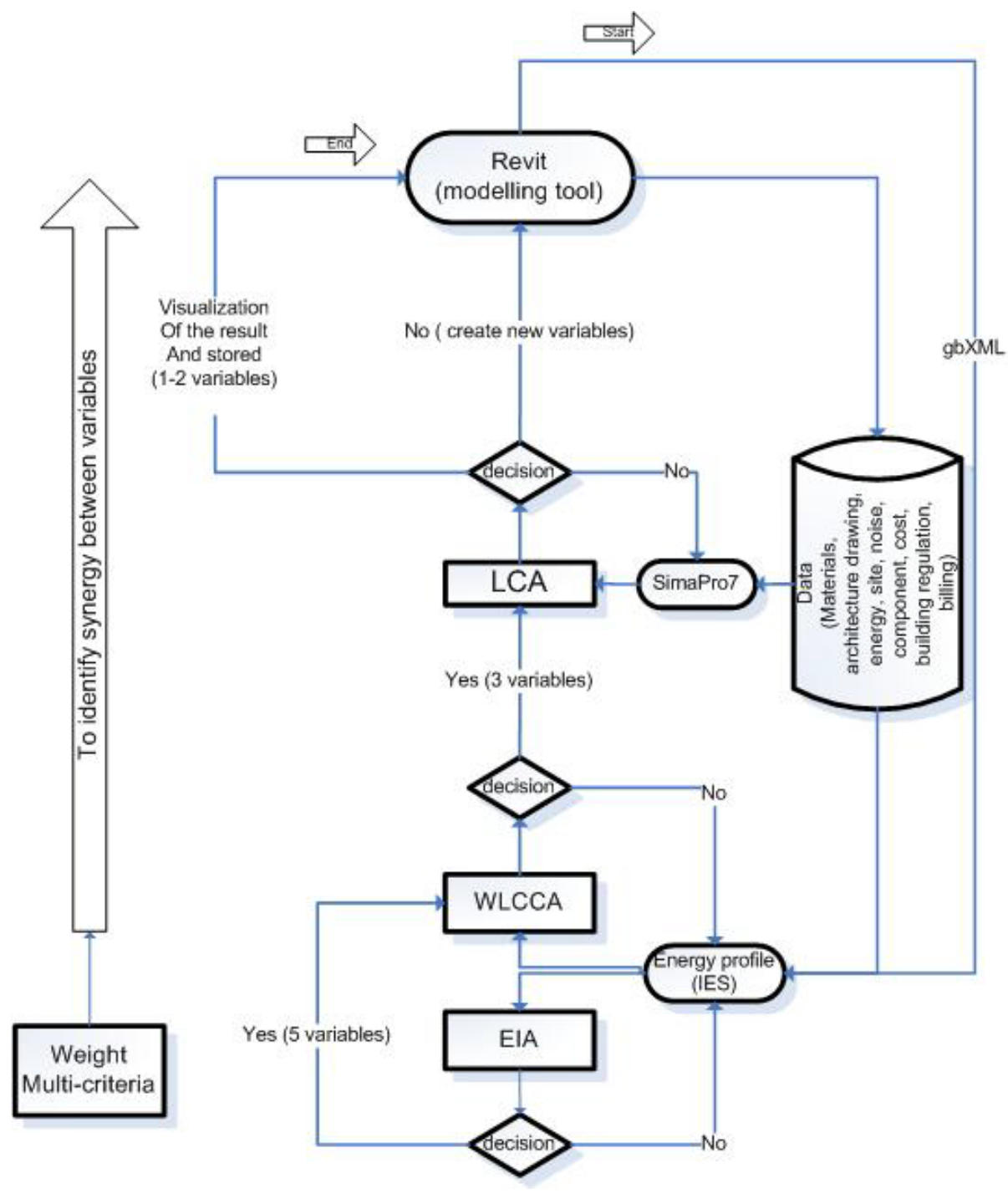

Figure 4: Methodology Framework

\subsection{The framework focuses includes:}

EIA: delivering building with excellent energy and $\mathrm{CO}_{2}$ performance requires a step change in our understanding of energy and carbon in buildings, so the project will focus on $\mathrm{CO}_{2}$ emission, waste management and land use.

WLCCA: the ratio of 1:5:200 has been set as the golden fraction of a building life cycle cost, 1 represents construction cost, 5 represents maintenance and 200 represents building operation cost as the business operation cost (Evans 1998). We need to reduce the ratio 200 and contribute to the green agenda by reducing carbon emission of building life cycle. The research adopts IES software tool to assess the EIA and WLCCA.

LCA: the research focuses on reuse, recycling materials and energy consumption in order to maximize energy performance and minimize environmental impact.

Smpio7 tool to assess the LCA

Why SimaPro7: <http://www.pre.nl/webdemo/new/EN/SimaPro_Intro_EN.html> [accessed 2009].

- The LCA explorer is structured according to the ISO 140140 LCA standard, so we can efficiently build and document our project. 


\section{Dawood, Lord and Dawood}

- Libraries with thousands of inventory process, these contain the environmental data for a product or process.

- SimaPro7 comes with the most used impact assessment methods, using these methods to calculate the environmental profile of any model.

Revit: This modelling software will be used as a main platform to visualize the model and the result. In addition, the framework will utilize the building information model (BIM) for design. Many other building models do not contain sufficient information for building performance analysis and evaluation. The Revit parametric building modeller represents the building as an integrated database of coordinated information.

Why Revit? Revit has many features that allow users the flexibility and freedom to design in a manner that does not constrain them to just 2D drawings. BIM technology and the parametric change engine are the two components which make Revit an incredible force in the (AEC) community (Krygiel et al. 2008).

\subsection{The method is divided into 4 phases:}

Phase1: The creation of building information model (BIM) using Revit Architecture software mirrors the real world of buildings, and helps to capture early design concepts. Also BIM is described as a set of information generated and maintained throughout the life cycle of building. The variables have different shapes, orientations, spaces, wall-window ratios, height and land use. This will affect the solar gain, lighting \& daylighting, thermal compliance, and value \& cost for heating and cooling loads according to sustainability issues, the orientation and the openings size of the variables play a crucial factor for solar gain.

Phase2: Using IES-VE to assess the environmental impact and the cost of the variables, we expect 2 or 3 variables will pass to the next phase if not we going to create new variables. The software can compare and contrast how different design choices affect the performance of a wide range of building elements, such as thermal, airflow and lighting performance, and energy/ $/ \mathrm{CO}_{2}$ consumption.

Phase3: Using LCA tool (SimaPro7) to assess the life cycle of the variables which have passed the previous phase. Revit is used either to visualize the variables, which pass this stage, or are to be modified start from the first phase.

The databases will play a vital factor in this method, containing: component costs, embedded energy, materials cost, climate data, building regulation data and architectural drawings. We can use existing data base and add new information to it.

Input of data relating to materials, occupancy, internal gains, climate, air movement and systems is managed via graphical interfaces and supported by extensive databases within IES. In addition the real data could be obtained from energy bills and manufacture's materials guide.

Phase4: Comparison with BREEAM compliance:

As described earlier, this study will have two targets: Firstly, integration of the three approaches (EIA, WLCCA and LCA). Secondly, to consider a standard outline design processes based on Royal Institute of British Architect (RIBA) work stages and associate these with environmental legislation including ISO standards and European Environmental Law. The results from the tools will be compared with BREEAM standards or other standard figures (Table 1).

The focus of the criteria is on the requirements and operation of the EIA, WLCCA and LCA. The main environmental requirements in EU are: (Streimikiene 2005)

- Promoting energy efficiency and use renewable energy sources

- Implementing economic tools of environmental regulation

- Targeting reduction of pollutants emissions into atmosphere

\subsection{Case study description:}

Model Data: Total conditioned floor area $=2144.74 \mathrm{~m}^{2}$, total conditioned volume $=6680.65 \mathrm{~m}^{3}$, number of room $=9$, climate file name, location Manchester, calculated at 16:00 on 04/Jun/08, Calc. Period: 01/Jan - 31/Dec

The method of integration of different criteria uses weightings decided by the architect or design team and the trade-off analysis for the criteria will appear on the compliance field. The optimum design has to have three compliances to pass the assessment by comparing the result of the criteria with the standard figures. The spreadsheet will take account of the number of compliances for the three methods (EIA, WLCCA and LCA), and automatically pass or fail the proposed design. The integration of the three approaches and BIM and develop synergy analysis to assist in decision making process (Table 1). 


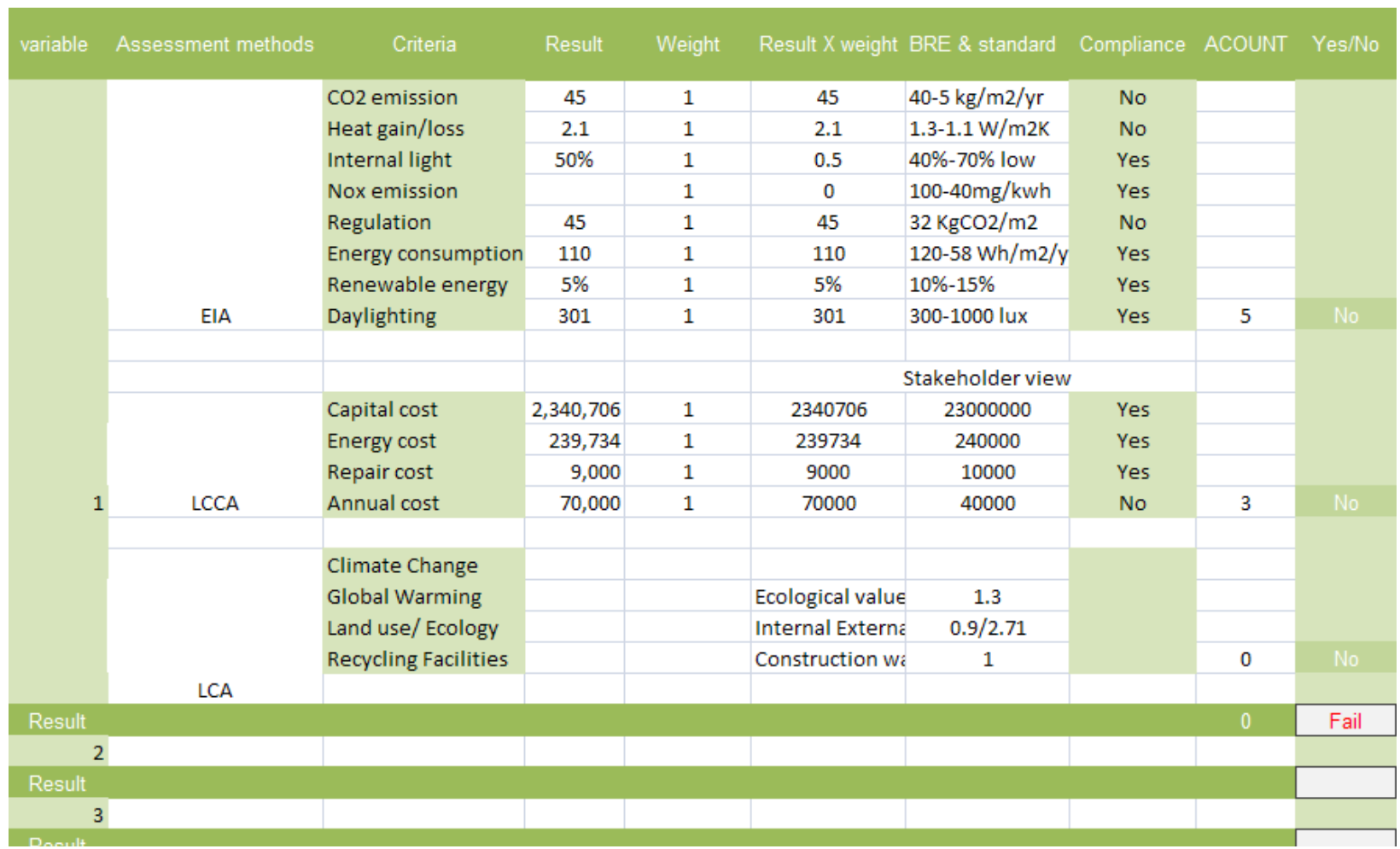

Table 1: Shows the result of case study to demonstrate the framework and the methodology, the results from the tools and BREEAM standards figures

\section{GAPS IN CURRENT KNOWLEDGE AND TOOLS}

Previous literature has identified gaps in current knowledge and tools. The development of a generic data framework will help decision-makers to accurately estimate the sustainability costs and benefits. The evaluation exercise on the sustainability tools has demonstrated a number of issues:

- Current evaluation tools are used after buildings are fully designed and therefore corrective decisions are costly and difficult to implement.

- Tools can be used to detect and calculate energy use but not always as a method of reducing them.

- There is no consideration of waste management and renewable energy that might be vital for sustainable buildings.

\section{CONCLUSIONS}

This paper aims to give an overall review of the knowledge and technologies in the research area. We present a framework, methodologies and technologies that will facilitate the integration of Environmental Impact Assessment, Whole Life Cycle Cost and Life Cycle Assessment using 3D and BIM technologies.

In addition, the paper focuses on building information modelling for sustainable design in current practice; many building models do not contain sufficient information for building performance analysis and evaluation. The Revit parametric building modeller represents the building as an integrated database of coordinated information. Revit Building customers have used building information modelling for a variety of sustainable design activities including design optimization, visualization, day-lighting, energy analysis, quantity takeoffs, and specifications management.

Our review of current literature and projects and the suitability of energy and assessment applied to built environment, has identified gaps in current knowledge and tools identify the current theories of data models of available IT tools that encourage and help decision-makers and the methodologies to assess environmental impact and to maintain an awareness of current developments,

Finally, a building could be designed with full knowledge of the environmental impact of the building over its life cycle by the use of VR images in the whole life cycle analysis and in the control of energy, emissions, ventilation, materials and 


\section{Dawood, Lord and Dawood}

orientation to estimate the operation and maintenance costs of project alternatives all through the facility's expected life-span. Also to assist the architects and building developers in decision making when designing buildings a linked database will ensure that the designer has all of the relevant information available that would be needed for the assessment of cost and environmental impact and options to reduce such an impact at the early design stage. Future developments of the research work will be to develop the prototype to verify the framework and to run scenario analysis. Also, use case studies to demonstrate the benefits to be derived from the use of the prototype and to compare the outputs with current practices.

\section{REFERENCES}

Alberto, H. N., and A. S. Flavio. 2007. Use of Simulation Tools for Managing Buildings Energy Demand. Proceeding: Building Simulation p.p 1883-1889

Agyeman, J., and B. Evans. 2004. Just Sustainable: The Emerging Discourse of Environmental Justice in Britain. The Geographical Journal, 170 (2):155-164.

Autodesk 2003. The Autodesk white paper-Building Information Modelling in Practice. Autodesk Company, US.

Autodesk 2005. The Autodesk white paper-Building Information Modelling in Practice. Autodesk Company, US.

Autodesk Revit Architecture 2008. Question and Answers < www. autodesk.com/revitarchitecture $>$ [accessed 2007].

CADAZZ, CAD Software History, Available via <http://www.cadazz.com/index.htm>, Review in October 2004.

Cole, R. J., N. Howard, T. Ikaga, and S. Nibel. 2005. Building Environmental Assessment Tools: current and future roles. Available via <http://www.sb05.com/academic/4\&5_IssuePaper.pdf>

Chirarattananon C., and J. Taveekun. 2004. An OTTV-based energy estimation model for commercial buildings in Thailand. Energy and Buildings, 36(7):680-689.

Department of Environment, Food and Rural Affair (DEFRA). 2005. Energy efficiency: the government plan's for action.

Eastman C.M., and A. Siabiris. 1995. Ageneric building product model incorporating building type information. Automation in Construction . 3: 283-304.

Eastman, C.M. 1999. Building Product Models: Computer Environments Supporting Design and Construction. Florida: CRC.

El-Haram m., J. Walton, M. Horner, C. Hardcastle, A. Price, J. Bebbington, and T. Atkin-Wright. 2005. Development of an Integrated Sustainability Assessment Toolkit. Engineering Sustainability, 158: 57-65

Fowke R., and D. Prasad. 1996. Sustainable development, cities and local government. Australian Planner, 33 : 6-66.

$\mathrm{Fu}$ C. 2005. Integration and Interoperability of IT Applications and Information in Construction-A Study in nD Modelling . PhD Thesis, University of Salford, UK.

Evans, R., R. Haryott, N. Haste, and A. Jones. 1998. The Long Term Costof Owning and Using Building. The Royal Academy of Engineering. Available via <www.arcom.ac.uk/publications/procs/ar2004-03730381 Hughes_et_al.pdf> [accessed 2008]

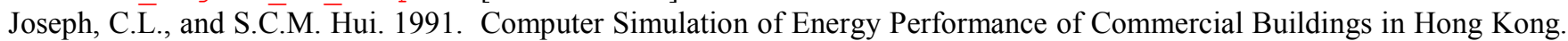
Building Simulation 93:129-135

Holmes, J., and G. Hudson. 2000. An evaluation of the objectives of the BREEAM scheme for offices. A local case study. The Cutting Edge 2000, University of Northumbria at Newcastle, UK.

Hui, S. C. M. and K. P. Cheung. 1997. Multi-year (MY) building simulation: is IT useful and practical. Building Simulation, 97: $133-140$

Kibert C. J., J. Sendzimir, and B. Guy. 2000. Construction ecology and metabolism: natural system analogues for a sustainable built environment. Construction Management and Economics, 18: 903-916.

Krygiel E., G. Demchak, and T. Dzambazova. 2008. Introducing Revit Architecture.

Loh E., N. Dawood, and J. Dean. 2007. Integration of 3D Tool with Environmental Impact Assessment 3D-EIA. 3rd Int'1 ASCAAD Conference on Em'body'ing Virtual Architecture [ASCAAD-07, Alexandria, Egypt]

Ness B, E. Urbel-Piirsalu, S. Anderberg, and L. Olsson. 2007. Categorising for Sustainability Assessment. Ecological Economics, 60 (3):498-508

Parkin S., F. Sommer, and S. Uren. 2003. Sustainable development: understanding the conceptual and practical challenge. Engineering Sustainability, 156: 19-26

Sage 1998. Risk management for sustainable development. <www. ieeexplore. ieee.org>. 4: 4815-4819.

Shelbourn, M., D. Bouchlaghem, C. Anumb, P. Carillo, M. Khlfan, and J. Glass. 2006. Managing knowledge in the context of sustainable construction. <http://itcon.org/2006/4/> [accessed 2009] 
Streimikiene D., C. Raltic, and G. Dainora. 2005. Energy indicators for sustainable development in Baltic States. Renewable and Sustainable Energy Reviews 11(5): 877-893. Available via <www.elsevier.com/locate/rser> [accessed 2008]

Sue-MoT 2003. Report from Sue-MoT workshop. Consortium Comprising Dundee, Caledonian and Loughborough Universities. (17 November 2003). Royal Statistical Society, London. Available via <www. sue-MoT.org.uk> [accessed 2008]

Sue-MoT 2004. Report from Sue-MoT workshop 2. Consortium Comprising Dundee, Caledonian and Loughborough Universities. (5 July 2004). Royal Statistical Society, London. <www. sue-MoT. org • uk> [accessed 2008]

U.S. Green Building Council, Mission Statement, 2004.<www.greenbuildingpages.com/press/GBPES.pdf> [accessed April, 2007].

WCED 1987. Our Common Future, Oxford University Press, Oxford, UK.

\section{AUTHOR BIOGRAPHIES}

SAAD DAWOOD (BSc) is a PhD researcher with Centre for Construction Innovation \& Research, School of Science and Technology, University of Teesside since Dec/2006. Working with team: Developing Middlehaven model in Middlesbrough, Nuttall project, using CAD, SketchUp, Revit, IES and Uc-win Road software. His research interest is in the area of integration of 3D with environmental impact analysis and green architectural. This has resulted in 3 published papers and the MPhil transfer report has been approved recently. His email is <f6135973@tees.as.uk> or <saad. dawood@btinternet.com>

RICHARD LORD (BSc, PhD) is Reader in Environmental Geochemistry \& Sustainability in the Clean Environment Management Centre at The University of Teesside. He received his $\mathrm{PhD}$ in geochemistry from the Open University for work related to the exploration for mineral deposits of chromium, platinum and other precious metals. After teaching Applied, Engineering and Environmental Geology for a decade he developed a particular interest in the environmental impact of resource exploitation, contaminated land and its sustainable redevelopment and use for renewable energy. His email is $<$ R. Lordetees.ac.uk $>$

NASHWAN DAWOOD (BSc, MPhil, PhD) is currently Director for the Centre for Construction Innovation \& Research, University of Teesside and Cecil M Yuill Professor of Construction management \& IT. Prof Dawood has spent many years as an academic and researcher within the field of construction management and the application of IT in the construction process. This has ranged across a number of research topics including information technologies and systems (4D,VR,Integrated databases), risk management, and business processes. This has resulted in over 170 published papers in refereed international journal and conferences, and research grants from British Council, Industry, Engineering Academy, EPSRC, DTI and construction industry companies, totaling about $£ 2,500,000$. Professor Dawood originated the CONVR conference series (Construction Applications of Virtual Reality: Current Initiatives and Future Challenges) and CONVR 2008 held in KL, Malaysia. His email is $\langle n \cdot n$. dawoodetees.ac.uk $>$ 